O AUTOR

Ismar de Oliveira Soares

Coordenador do Núcleo de Comunicação e Educação (NCE) do Departamento de Comunicações e Artes da ECA-USP. Vice-Presidente

(regional) do World Council for Media

Education (WCME).E-mail: ismar@usp.br

\title{
EDUCOMUNICAÇÃO: UM CAMPO DE MEDIAÇÕES
}

Firma-se, principalmente na América-Latina, um referencial teórico que sustenta a inter-relação comunicação/educação como campo de diálogo, espaço para o conhecimento crítico e criativo, para a cidadania e a solidariedade

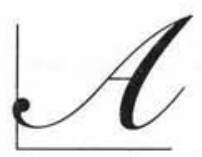

inda não se passaram seis anos da explosão comercial da Internet e mais da metade das universidades americanas já estão oferecendo algum tipo de educação a distância. Através do uso das modernas tecnologias da comunicação, prevê-se que, para meados da primeira década do novo milênio, cerca de $60 \%$ do ensino do país esteja sendo ministrado fora dos ambientes tradicionais, ou seja, inteiramente através do ciberespaço.

Tal perspectiva preocupa as autoridades e está mobilizando os centros de pesquisa dos Estados Unidos. Entre as questões em discussão está a perda do controle sobre a educação por parte de seus principais agentes: os professores e os alunos, uma vez que a chamada indústria da educação está vislumbrando negócios na área que chegam à astronômica cifra de 200 bilhões de dólares.

Em decorrência disso, outra questão ganha relevância e diz respeito às condições que os professores têm de conviverem com o novo modus comunicandi, próprio das novas tecnologias e inerentes à natureza das comunidades virtuais. Em outras palavras, discute-se sobre os atuais e os vindouros paradigmas da educação em seu confronto/associação com o mundo da informação e sobre o papel do professor/instrutor nesta revolução tecnológica. Ou eles conseguem decifrar o que está ocorrendo e se preparam para assumir papel protagônico no processo ou serão substituídos por quem se disponha a servir o sistema que está sendo 
implantado. E para muitos especialistas, a questão-chave não está nas tecnologias, mas no próprio modelo de comunicação adotado. Para Rena Pallof e Keith Pratt, autores do celebrado livro Building Learning Communities in Cyberspace (Construindo a comunidade educativa no ciberespaço), comunicação é o conceito-chave quando se fala em educação e tecnologia: "Nós concluímos, através de nosso trabalho com a Internet, que a construção da comunidade educativa (Learning Community) - com os professores participando em igualdade de condições com seus alunos - é a chave do sucesso de todo o processo" '. Para estes autores, o momento está maduro e suficientemente adequado para uma profunda revisão do sentido da ação comunicativa presente no ato educativo - quer o presencial, quer o a distância - o que assinala, naturalmente, para um ponto de mutação em direção ao que ousamos denominar como o campo da inter-relação comunicação/educação.

Não é evidente, à primeira vista, especialmente ao observador da cena norteamericana, que comunicação e educação possam vir a integrar-se, em algum momento, num campo específico e autônomo de intervenção social. A história nos ensina, na verdade, que tanto a educação quanto a comunicação, ao serem instituídas pela racionalidade moderna, tiveram seus campos de atuação demarcados, no contexto do imaginário social, como espaços independentes, aparentemente neutros, cumprindo funções específicas: a educação administrando a transmissão do sa- ber necessário ao desenvolvimento social e a comunicação responsabilizando-se pela difusão das informações, pelo lazer popular e pela manutenção do sistema produtivo através da publicidade.

No entanto, no mundo latino, certa aproximação foi constatada, graças à contribuição teórico-prática de filósofos da educação como Célestin Freinet ou Paulo Freire, ou da comunicação, como Jesús Martín-Barbero e Mário Kaplún. Colaboraram também para esta aproximação o avanço das conquistas tecnológicas e o barateamento dos custos dos equipamentos, o que levou grupos ativos e organizados de especialistas a iniciarem um irreversíviel processo de aproximação entre estes dois campos.

\section{EDUCAÇÃO E RAZÃO TÉCNICA}

A Modernidade nasceu com a instituição da crença nas possibilidades da razão, capaz de transformar a sociedade pela dominação da natureza pelo homem. Ao mesmo tempo, impôs a uniformização das representações sociais coletivas e a massificação das aspirações e das mentalidades como forma de controle da opinião pública. Para tanto, a sociedade industrial conformou a educação (para sedimentar e legitimar a ordem social que queria ver estabelecida), fazendo, por outro lado, uma apropriação do discurso midiático, usando-o como seu mais poderoso instrumento disciplinador coletivo ${ }^{2}$.

Por suas incongruências, contudo como a destruição do ecossistema em nome da racionalidade econômica ou a

1. PALLOFF, Rena \& PRATT, Keith. Building Learning Communities in Cyberspace (Construindo a comunidade educativa no ciberespaço). San Francisco: Jossey- Bass Publishers, 1999. p. XVI.

2. MILAN, Yara Maria Martins. Comunicação e educação: um ponto de mutação no espaço de confluência. www.eca.usp.br/nucleos/nce 
violência que eliminou vidas sem conta nas pequenas e grandes guerras do século por causas que a história revelou irrelevantes - a razão iluminista acabou por perder legitimidade frente aos olhos de milhões de pessoas. Nesse sentido, a própria sociedade foi obrigada a buscar na dinâmica da denominada cultura da PósModernidade referenciais mais adequados que expliquem as mudanças pelas quais a sociedade em geral e as pessoas em particular estão passando.

\section{A Pós-Modernidade não substituiu, mas apenas} reagendou a cosmovisão própria da Modernidade. Continua a reforçar a crença na ordem mundial, agora comandada por uma nova razão, a razão técnica, e pelo predomínio da informação.

Por outro lado, a Pós-Modernidade assinalou para a liberalização das consciências através do reconhecimento da autonomia individual e da valorização do subjetivismo. Em termos psicossociais, pela razão técnica, o real se converte em virtual, o que significa a concretização dos desejos e aspirações humanas em maneiras analógicas, através dos simulacros presentes no cotidiano da produção simbólica do sistema de comunicação. Por outro lado, o rápido desenvolvimento tecnológico permitiu, sem sombra de dúvidas, que a informação viesse a representar, nos dias atuais, o fator-chave dos processos produtivos de bens e serviços ${ }^{3}$.

$\mathrm{O}$ pensador francês Pierre Furter ${ }^{4}$, ao explicar a perplexidade dos educadores, traça um paralelo entre as práticas educativas e comunicativas no atual período de transição, garantindo que o que experimentamos não é outra coisa senão uma verdadeira mudança de paradigmas: o discurso sobre a educação que a definia como base da construção da democracia moderna e do progresso dos povos está sendo substituído pelo discurso sobre a excelência e a irreversibilidade da informação. Em outros termos, há uma valorização social do mundo da comunicação e uma negação do mundo da educação tradicional.

Reconhece-se, por outro lado, que a educação - a síntese de um longo processo civilizatório - chega aos albores do século XXI com um enorme cabedal de serviços prestados à humanidade, sem, contudo, ter gestado e gerenciado processos de inter-relação cultural que a coloque em sintonia com o novo mundo que a rodeia.

A educação, representando o tempo do pensamento lógico, seriado, geométrico, basicamente livresco (identificada com a era fordista ${ }^{5}$ ), estaria, pois, em crise. Já a

3. ALONSO, José Antônio Dacal. Las grandes líneas-fuerza que configuran el horizonte moderno. (As grandes linhas-força que configuram o horizonte moderno) México: Umbral XXI, número especial 3, 1996.

4. FURTER, Pierre. Comunicação e Educação, repensando os paradigmas. XIX Congresso Brasileiro de Comunicação Social, organizado pela ABT - Associação Brasileira de Tecnologia Educacional e UCBC — União Cristã Brasileira de Comunicação Social, Rio de Janeiro, nov. 1995. (Mimeo) 
instituição denominada de comunicação de massa, consolidando um pensamento fragmentado e uma cultura aleatória, essencialmente audiovisual, estaria em alta no imaginário social. A comunicação de massa representaria o eixo que atravessa as novas condições da sociedade de pensar e organizar.

Furter recorda, por outro lado, que, enquanto o mundo da educação se baseia no espaço local (a escola do bairro, da cidade) e num sistema escolar regido por normas conhecidas de seus usuários, traduzindo formas nacionais de poder; o mundo da comunicação de massa paira sobre as nações, sem território próprio (desterritorializado), sem donos visíveis (seu centro de controle está nas organizações transnacionais), refletindo as novas formas planetárias de poder. Ainda segundo o pesquisador francês, enquanto o sistema escolar se apresenta como um conjunto de instituições que depende direta ou indiretamente do Estado, tendendo a ser coerente, organizado, burocrático e hierarquizado, voltando-se a públicos determinados, tendo como missão a sistematização e a transmissão de conhecimentos especializados, o sistema de meios se caracteriza por ser um conjunto de instituições com vínculos transnacionais, a serviço de públicos abertos, desburocratizado, tendo como conteúdo principal o lazer e um conjunto de mercadorias oferecidas ao consumo.

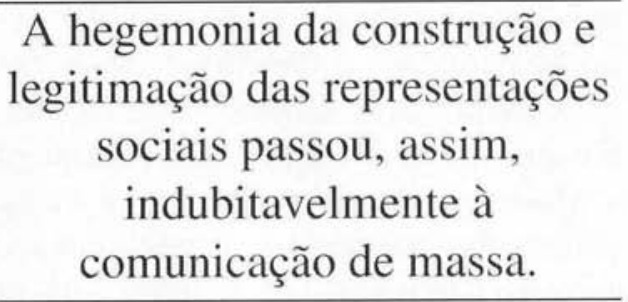

Seu referencial cognitivo baseia-se justamente no surgimento de uma realidade virtual, acessível a imensas audiências, criando a crença na existência de uma comunidade (também virtual) entre produtores e receptores.

Com um tempo próprio (o presente) e um espaço desterritorializado (o ecossistema virtual ou ciberespaço), a comunicação de massa mantém, como garantem os estudos de recepção, um pé na realidade, ainda que esta seja o universo fluido do imaginário e das paixões humanas. A comunicação de massa faz as pessoas sentirem-se, de alguma forma, cidadãs de um mundo em mutação.

\section{MODERNIDADE VERSUS PÓS-MODERNIDADE?}

Estaríamos vivendo o desmanche da civilização do livro e dos conteúdos seriados e sistematizados, entrando no mundo veloz, contingente, fluido e mutável da civilização audiovisual, cuja marca é a incerteza e a expectativa do novo, a cada minuto?

Compreender a realidade e buscar um novo sentido para a educação num mundo 
regido pelas contradições do confronto entre Modernidade e Pós-Modernidade faz parte da missão do filósofo e do educador. É o que garante Fernando Font, para quem a Modernidade, ao adotar uma visão universalista nas normas sociais e morais, cometeu o grave erro de dividir o homem em razão e sensibilidade, obrigando a educação formal a optar pela hegemonia da razão. Adverte, contudo, para o perigo igualmente mutilante de se tentar, num novo projeto pedagógico, a recuperação da sensibilidade ao custo da pura e simples castração da razão. "Não é possível seguir acreditando numa razão ditatorial e deixar-se levar por ela. É necessário recuperar a sensibilidade, caminhar em direção a uma nova razão capaz de pensar a parcialidade, a individualidade, o pluralismo e que não aprisione a riqueza da vida nos moldes estreitos de uma conceitualização

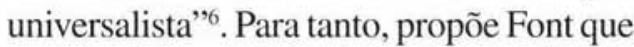
se considere a adoção do conceito de "inteligencia sentiente" (no original, em castelhano), explicando: dada a unicidade do ser humano, a faculdade de apreensão da realidade é operada conjuntamente pela materialidade dos sentidos e pela capacidade de intelecção abstrata do homem. Por este mesmo princípio da unicidade, o próprio ato de sentir (a impressão da realidade) converte-se em ato de aprender sem necessidades de conceitos ou de racionalizações. A razão posteriormente reatualizará o real para descobrir suas estruturas mais profundas que não estão desvendadas nesse ato radical de inteligência que é a im- pressão da realidade.

Para o filósofo mexicano, de nenhuma maneira a razão (responsável pelo descobrimento e apreensão de estruturas do real mediante o pensar e os conceitos) é o mais fundamental do ser humano: "Ela - a razão - não nos põe na realidade. $\mathrm{O}$ que nos faz pessoas, seres humanos, é o estar na realidade e não o uso dos conceitos e das teorias. Antropologicamente, por conseguinte, deveríamos mudar a tradicional definição de homem dada por Aristóteles ('O homem é um animal racional'). Agora, deveríamos nos referir ao homem como o animal de realidades. Não é a mesma coisa, pois, viver na realidade e "viver nas idéias, na razão ${ }^{7}$. Ele reconhece, assim, certos méritos no pensamento pós-moderno, entre os quais o de repensar a natureza da racionalidade humana.

Nessa mesma linha propositiva, o Prof. Leonardo Méndez Sánchez ${ }^{8}$, da Universidade Ibero-Americana do México, relembra que a educação necessita reverse a partir de algumas metas, basicamente voltadas para valorização do sujeito e da sensibilidade do processo educativo, quais sejam: a) o estabelecimento de um novo conceito de razão geradora de uma racionalidade plural que rompa a estreiteza até agora criticada; b) o desenvolvimento de uma visão a partir da qual a riqueza e a diversidade da vida possam ser entendidas e exploradas cabalmente. Haveria que sinalizar, segundo ele, que a vida do homem é irredutível a qualquer universalismo.

6. FONT, Fernando Fernandez. Una propuesta alternativa. Mas allá de la modernidade? (Uma proposta alternativa. Além da Modernidade?) México, DF: Umbral XXI, especial 3, 1996.

7. FONT, Fernando Fernandez. Una propuesta ... op. cit. p. 24.

8. SANCHEZ, Leonardo Mendez. Reflexiones en torno a la postmodernidad y la prática educativa (Reflexões em torno da Pós-Modernidade e a prática educativa). México, DF: Umbral XXI, Número especial 3. 1996. 


\section{EDUCAÇÃO,CIDADANIAECONSUMO}

Francisco Gutiérrez, ao buscar resposta à pergunta "para que educar na era da informação?", propõe que a escola contemporânea se volte mais para a sensibilidade humana que para uma racionalidade abstrata e distante. E para que este sentido aflore com maior naturalidade e a comunicação se faça, o autor propõe que a escola eduque para a incerteza, para usufruir a vida, para a significação, para a convivência e, finalmente, para a apropriação da história e da cultura ${ }^{9}$.

A apropriação da cultura por parte dos usuários dos meios de informação pode constituir-se em plataforma para uma ação educativa coerente com as necessidades atuais.

Seguindo esta linha, Néstor GarciaCanclini coloca em meridiana evidência a necessidade de o sistema educativo envolver-se - em seu confronto com a moderna produção da cultura - com o mercado, o consumo e o sistema de comunicação que o serve.

No que diz respeito à apropriação da cultura, Garcia Canclini entende que uma verdadeira revanche cultural vem ocorrendo pelas mãos dos próprios usuários e receptores dos meios. Para ele, o consumo desenfreado tem servido principalmente para refletir e fazer pensar ${ }^{10}$.

O consumo é, diz, um conjunto de processos socioculturais em que se realizam a apropriação e o uso de produtos materiais e espirituais. Fala-se em consumo de sabonetes, como em consumo da fé. No consumo se manifesta uma racionalidade, uma visão de mundo. Existe uma lógica na construção dos signos de status do consumidor. O consumo serve, sobretudo, para distinguir as pessoas, as famílias, os educandários, as classes sociais: "A lógica que rege a apropriação dos bens enquanto objetos de distinção não é a da satisfação de necessidades, mas sim a da escassez de bens e da impossibilidade de que outros os possuam" "I. Segundo Garcia-Canclini, o consumo é um processo planejado em que os desejos se transformaram em demandas e em atos socialmente regulados. Nada, portanto, que se pareça com o espontaneísmo de consumidores autônomos e irreverentes.

Ele observa, por outro lado, o poder manipulador do mercado, principalmente na destruição e subversão das ferramentas de leitura do mundo. "Há poucos anos pensava-se o olhar político como uma alternativa de leitura do mundo (imaginava-se que mudando as estruturas políticas, estar-se-ia transformando as relações sociais, tornandoas mais justas). O mercado desacreditou esta atividade de uma maneira curiosa, não apenas lutando contra ela ou exibindo-se como mais eficaz para

9. GUTIÉRREZ, Francisco. La mediación pedagógica y la tecnologia educativa. (A mediação pedagógica e a tecnologia educativa). Rio de Janeiro, set./dez., v. 25, 1996. p. 132-133.

10. GARCIA-CANCLINI, Néstor. Consumidores e cidadãos. Conflitos multiculturais da globalização. Rio de Janeiro: Editora da UERJ, 1995.

11. GARCIA-CANCLINI, Néstor. Consumidores... op.cit. p. 17. 
organizar as sociedades, mas também devorando-a, subvertendo a política às regras do comércio e da publicidade, do espetáculo e da corrupção"12. Os homens e mulheres já se mostram, contudo, mais atentos. De acordo com o autor, a reação esboçada, aqui e ali, principalmente no campo educacional, deve transformar-se em ato político.

\section{O consumo deve ser assumido como exercício da cidadania.}

"É necessário dirigir-se ao núcleo daquilo que na política é relação social: o exercício da cidadania"13. A proposta leva, naturalmente, a uma leitura crítica do consumo, seguida de uma retomada do interesse pelo público, pelo coletivo. "Vincular consumo com cidadania requer ensaiar um reposicionamento do mercado na sociedade, tentar a reconquista imaginativa dos espaços públicos" ${ }^{14}$.

Os autores analisados deixam evidente que uma relação entre a comunicação e a educação já vem sendo operacionalizada, quer pelo uso dos instrumentais tecnológicos, quer pela ação política de profissionais que têm na busca do exercício da cidadania a razão de ser de seus atos.

Nesse sentido, a nova racionalidade, sugerida por Furter, Font, Sánchez, Gutierrez e Canclini, já anteriormente proposta por Freire, representa sólido pressuposto político-pedagógico para se pensar a inter-relação comunicação e educação. Chegará, contudo, esta interrelação, a ser reconhecida como um novo campo ou continuará a ser tomada tão somente como mera interface entre dois campos tradicionais?

Para os defensores da tese da simples interface, tanto comunicação quanto educação são campos historicamente constituídos, definidos, visíveis e fortes. Desde sempre, o homem estabeleceu processos de comunicação entre si, usando para isso recursos diferentes. A educação, para os mesmos pesquisadores, é legitimada na esfera do oficial, do bem comum, da necessidade mínima de construção da cidadania, enquanto a comunicação é reconhecida como inerente ao sistema liberal e transferida para a iniciativa privada.

Educação e comunicação se distanciam, também, pelo tecido de seus discursos. $\mathrm{O}$ discurso educacional é mais fechado e enquadrador, oficial, mais autorizado. Validado por autoridades, não é questionado. Neste sentido, é autoritário, posto que é selecionado e imposto em forma de currículo a alunos e professores. O discurso comunicacional, ao contrário, é desautorizado, desrespeitoso e aberto, no sentido de que está sempre à procura do novo, do diferente, do inusitado. Enquanto a educação está presa ao Estado - fragilizado, sem poder e pobre -, naquilo que o Estado tem de pior, que é a burocracia; a comunicação vincula-se ao mercado, aprimora-se constantemente, tem liberdade na construção do seu "currículo" e de sua forma de agir. 
Por todos esses arrazoados, a educação e a comunicação jamais poderiam integrar-se, sob a suspeita de estarem perdendo sua identidade e sua razão de $\operatorname{ser}^{15}$.

Os que defendem posição oposta pelo reconhecimento de um campo integrador - afirmam que o mais importante e decisivo eixo construtor do novo campo é a interdiscursividade ${ }^{16}$. Para estes, as investigações nesta área de confluência têm a polifonia discursiva como seu elemento estruturante.

Daí a necessidade de um aprofundamento teórico deste referencial analítico que supere a análise pontual de práticas que tematizam prioritariamente a incorporação das tecnologias da comunicação e da informação no processo educativo. Trata-se da busca de um discurso-transverso, na expressão de Pêcheux ${ }^{17}$.

\section{UM CAMPO DE DIÁLOGO E INTEGRAÇÃO}

Maria Aparecida Baccega, diretora da revista Comunicação \& Educação, refletindo sobre a necessária articulação da comunicação com outras áreas do saber, afirma que hoje as Ciências Humanas e Sociais estão efetivamente incorporadas ao campo da comunicação, constituindo-o. Desse modo, a apropriação das Ciências Humanas e Sociais para a constituição desse campo se dá num processo espiralado de metassignificação, que redunda, obviamente, em novas postu- ras epistemológicas ${ }^{18}$.

Para identificar as complexas similitudes entre os possíveis modus comunicandi e o modus educandi necessitamos retornar a um dos pioneiros na inter-relação comunicação/educação no cenário latinoamericano: Paulo Freire, que, no clássico texto Extensão ou comunicação?, focaliza os processos comunicacionais que se inserem no agir pedagógico libertador. Paulo Freire afirma que o homem é um ser de relação e não só de contatos como o animal; não está apenas no mundo, mas com o mundo.

Neste contexto, a comunicação é vista como um componente do processo educativo e não através do recorte do "messianismo tecnológico"19. Alerta Freire, nessa direção, que, embora todo desenvolvimento seja modernização, nem toda modernização é desenvolvimento ${ }^{20}$. Assim, o gerundivo latino modus referese a uma forma de relação estratégica performativa $^{21}$ que se estabelece entre comunicação e educação, através do agir.
Trata-se de um modo de interação que afasta a ótica puramente instrumental da tecnologia comunicativa e informativa.

Sob esta perspectiva, a comunicação passa a ser vista como relação, como modo

16. LAURITI, Nádia C. Comunicação e educação: território de interdiscursividade. www.eca.usp.br/nucleos/nce

17. PÉCHEUX, Michel. Semântica do discurso. Uma crítica à afirmação do óbvio. Campinas: Editora da UNICAMP, 1988.

18. BACCEGA, Maria Aparecida. Comunicação e linguagem. Discurso e Ciência. São Paulo: Moderna, 1998.

19. GOMEZ, Margarida Victória. Paulo Freire: re-leitura para uma teoria da informática na educação. www.eca.usp.br/ nucleos/nce

20. FREIRE, Paulo. Extensão ou comunicação? Rio de Janeiro: Paz e Terra, 1976.

21. AUSTIN. Quand dire c'est faire. (Quando dizer é fazer) Paris: Seuil,1970. 
dialógico de interação do agir educomunicativo. "Ser dialógico é vivenciar o diálogo, é não invadir, é não manipular, é não sloganizar. O diálogo é o encontro amoroso dos homens que, mediatizados pelo mundo, o pronunciam, isto é, o transformam e, transformando-o, o humanizam"22. Para o saudoso educador nãoé possível compreender o pensamento fora de sua dupla função: a cognoscitiva e a comunicativa.

É igualmente oportuno retornar a Mário Kaplún ${ }^{23}$, para quem a "Comunicação Educativa" existe para dar à educação métodos e procedimentos para formar a competência comunicativa do educando.

Não se trata, pois, de educar usando o instrumento da comunicação, mas que a própria comunicação se converta no eixo vertebrador dos processos educativos: educar pela comunicação e não para a comunicação. Dentro desta perspectiva da comunicação educativa como relação e não como objeto, os meios são ressituados a partir de um projeto pedagógico mais amplo.

Os dois educomunicadores - Freire e Kaplún-vinculam os espaços do contexto sociocultural, da comunicação e da educação como uma relação, não como uma área que deva ter seu objeto disputado ${ }^{24}$.

De nossa parte, afirmamos que é justamente a relação o elemento constitutivo do novo campo. Quanto à disputa, não existe, desde que se reconheça que os tradicionais campos continuam mantendo sua vigência, dentro do paradigma Iluminista que os criou.
Martín-Barbero ${ }^{25}$ contribui com essa discussão, delineando o conceito de destempo. Para demonstrar os conflitos entre as diferentes temporalidades, parte da classificação proposta pela antropóloga americana Margaret $\mathrm{Mead}^{26}$, que estabelece uma distinção entre três tipos diferentes de cultura: a pós-figurativa em que os jovens aprendem primordialmente através dos adultos; a cofigurativa, que tem como modelo norteador a conduta dos contemporâneos, onde tanto jovens como adultos aprendem na conjuntura das relações sociais em que estão envolvidos; e a pré-figurativa em que os adultos também aprendem com os jovens, onde os pares substituem os pais, promovendo uma ruptura de gerações sem precedentes. A autora observa que as sociedades primitivas e os redutos ideológicos e religiosos são principalmente pós-figurativos e extraem a autoridade do passado. Já as grandes civilizações, que necessariamente desenvolveram técnicas para a incorporação das mudanças, recorreram tipicamente a alguma forma de aprendizagem cofigurativa a partir dos pares, dos grupos com poder de influência.

A partir dos anos 60 emerge
uma cultura pré-figurativa em
que os pares substituem os pais,
instaurando uma ruptura entre
as gerações.


É preciso criar novos modelos de relação pedagógica e comunicativa para que os adultos ensinem não o que os jovens devem aprender, mas como devem fazê-lo; e não como devem comprometer-se, mas qual é o valor do compromisso. A partir deste referencial, Martín-Barbero analisa os destempos da educação, mostrando que a comunicação pedagógica, apoiada no texto impresso, encarna e prolonga a temporalidade deste tipo de saber. Ela apóia-se na transmissão de conteúdos reconstituíveis e se vale de um modelo mecânico de leitura unívoca e passiva que afasta a dialogicidade. Proclama, assim, o império das letras em detrimento da imagem que hoje dinamiza os processos de comunicação.

O tempo pedagógico faz deste modus comunicandi uma forma de exercício de poder, já que a autonomia do leitor e a possibilidade de um ecossistema comunicativo marcado pela dialogicidade implica a descentralização da palavra autorizada e a transformação das relações sociais internas do espaço escolar.

Como se pode inferir, a discussão sobre o tempo pedagógico mexe com questões nucleares como acomodação e/ou ruptura de gerações, conflitos, alienação, resistências, insurgências que, polifonicamente, insistem em aparecer nas entrelinhas. Analisando, ainda, a temporalidade na comunicação, MartínBarbero considera a tecnicidade midiática como uma dimensão estratégica da cultura, vista, muitas vezes, com desconfiança pela escola porque funciona como elemento desequilibrador das ambiências das aprendizagens herdadas por tradição. Os meios deslocam as fronteiras entre razão e imaginação, saber e informação, arte e ciência e possibilitam o exercício de um tempo virtual que libera $o$ aqui $e o$ agora, inaugurando novos espaços e novas velocidades.

Estamos, assim, como analisam os pesquisadores do Núcleo de Comunicação e Educação - NCE, da ECA/USP ${ }^{27}$, diante de um processo, de um modus operandi capaz de inaugurar posturas teóricas e práticas que se situam para além das tradicionais paredes paradigmáticas, reconceitualizando a relação entre educação e comunicação e direcionando-a para uma educação cidadã emancipatória. O que esperamos é que seja forte para romper com a narrativa dominante de uma cidadania associada meramente ao consumo.

\section{CONSOLIDAÇÃO DE UM NOVO CAMPO}

A hipótese central com a qual a pesquisa desenvolvida pelo NCE/ECA/USP trabalhou foi a de que efetivamente já se formou, conquistou autonomia e encontra-se em franco processo de consolidação um novo campo de intervenção social a que denominamos de inter-relação comunicação/educação.
Tal inter-relação,
ou simplesmente

Educomunicação, não foi

tomada tão somente como uma

nova disciplina a ser

acrescentada nos

currículos escolares. 
Ao contrário, ela está inaugurando um novo paradigma discursivo transverso, constituído por conceitos transdisciplinares, como apontamos anteriormente.

Esta foi justamente a segunda hipótese: o novo campo, por sua natureza relacional, estrutura-se de um modo processual, midiático, transdisciplinar e interdiscursivo, sendo vivenciado na prática dos atores sociais, através de áreas concretas de intervenção social.

A interdiscursividade, vale dizer, o diálogo com outros discursos, é a garantia da sobrevivência do novo campo e de cada uma das áreas de intervenção, ao mesmo tempo que vai permitindo a construção de sua especificidade. Este interdiscursoé multivocal e o seu elemento estruturante é a polifonia. A alteridade é a dimensão constitutiva deste palco de vozes que polemizam entre si, dialogam ou complementam-se.

Como terceira hipótese, reconhecemos que o campo da inter-relação comunicação/educação se materializa em algumas áreas de intervenção social, tais como:

a) A área da educação para a comunicação, constituída pelas reflexões em torno da relação entre os pólos vivos do processo de comunicação (relação entre os produtores, o processo produtivo e a recepção das mensagens), assim como, no campo pedagógico, pelos programas de formação de receptores autônomos e críticos frente aos meios. Existem distintas vertentes na área da educação para a comunicação, o que compreende desde posturas defensivas, de cunho moralista, até projetos que se caracterizam por implementar procedimentos voltados para a apropriação dos meios e das linguagens da comunicação por parte das crianças e jovens. No mundo ibero- americano, a explicitação da teoria das mediações, especialmente por MartínBarbero, permitiu uma visão mais lúcida do processo de recepção, promovendo importante mudança na pedagogia da educação para os meios;

b) A área da mediação tecnológica na educação, compreendendo o uso das tecnologias da informação nos processos educativos. Trata-se de uma área que vem ganhando grande exposição devido à rápida evolução das descobertas tecnológicas e de sua aplicação ao ensino, tanto o presencial quanto o a distância. Sabemos que os recursos tecnológicos clássicos, como o rádio e a televisão, tiveram dificuldade de ser absorvidos pelo campo da educação, especialmente por seu caráter lúdico e mercantil. Tal fato foi o principal responsável pela resistência dos educadores em dialogar com as tecnologias. O computador veio abalar essa dicotomia, pois possui em si mesmo os meios de produção de que o pequeno produtor cultural - 0 aluno e o professor - necessitam para seu trabalho diário. Devemos lembrar que a grande maioria dos sites hoje existentes são produzidos e dirigidos por centros de pesquisas científicas;

c) A área da gestão da comunicação no espaço educativo, voltada para o planejamento, execução e realização dos processos e procedimentos que se articulam no âmbito da comunicação/ cultura/educação, criando ecossistemas comunicativos. O conceito de ecossistema comunicacional designa a organização do ambiente, a disponibilização dos recursos, o modus faciendi dos sujeitos envolvidos e o conjunto das ações 
que caracterizam determinado tipo de ação comunicacional. No caso, a família, a comunidade educativa ou uma emissora de rádio criam, respectivamente, ecossistemas comunicacionais. Os indivíduos e as instituições podem pertencer e atuar, simultaneamente, em distintos ecossistemas comunicacionais, uns exercendo influências sobre os outros. A gestão da comunicação nos espaços educativos produz-se tanto nos ambientes voltados para programas escolares formais, quanto naqueles dedicados ao desenvolvimento de ações não-formais de educação, como nas emissoras de rádio e de televisão educativas, nas editoras e centros produtores de material didático, nas instituições que administram programas de educação a distância e nos centros culturais.

d) A área da reflexão epistemológica sobre a inter-relação comunicação/educação como fenômeno cultural emergente. É, na verdade, a reflexão acadêmica, metodologicamente conduzida, que vem garantindo unicidade às práticas da Educomunicação, permitindo que o campo seja reconhecido, evolua e se legitime. A própria pesquisa que estamos realizando situa-se nesta área, assim como boa parte das reflexões produzidas pelos pensadores de quem nos servimos para a constituição do corpo teórico do trabalho.

Cada uma dessas áreas tem sido tradicionalmente assumida como espaço vinculado ao domínio, quer da educação quer da comunicação.
Defendemos que cada uma

dessas áreas e seu conjunto sejam pensados e promovidos a partir da perspectiva da Educomunicação.

Entendemos, por outro lado, que as quatro áreas não são excludentes, nem são as únicas. Representam, apenas, um esforço de síntese, uma vez que parecem aglutinar as várias ações possíveis no espaço da inter-relação em estudo.

Para comprovar as hipóteses levantadas a respeito da presumível emergência do campo da inter-relação comunicação/educação, a equipe do Núcleo de Comunicação e Educação - NCE realizou uma pesquisa cujos instrumentos investigatórios foram: aplicação de questionário exploratório junto a uma amostragem significativa (400 questionários respondidos por 178 especialistas de 12 países do continente); entrevistas com 25 especialistas latino-americanos de reconhecido renome, além da promoção de workshops, seminários e de congressos para coleta de dados posteriormente incorporados ao trabalho ${ }^{28}$.

Através dos questionários, foi possível levantar o interesse dos pesquisados sobre o tema em questão, seu perfil profissional, suas expectativas com relação ao avanço teórico do campo. Das entrevistas, colheu-se um rico conjunto de histórias de vida relacionadas com o tema, com

28. O trabalho sobre o campo da inter-relação comunicação e educação e sobre o perfil do Educomunicador foi possível graças à dedicação dos pesquisadores do Núcleo de Comunicação e Educação do Departamento de Comunicaçōes e Artes da Escola de Comunicações e Artes da USP, sob a coordentação de Patrícia Horta Alves, Fernando Peixoto Vieira, Eliany Salvatierra e Angela Schaun. Elaboraram textos complementares, os pesquisadores: Maria Cristina Costa, Yara Maria Martins Nicolau Milan, Nádia Lauriti, Margarita Victória Gomez, Edson Gabriel Garcia, Manoela Lopes Lourenço, Vânia Valente. Ver mais informações sobre a pesquisa no site: www.eca.usp.br/nucleo/nce 
os especialistas emitindo opiniões sobre as ações e pesquisas na área, referendando bibliografias e descrevendo seus projetos e trabalhos. Nos workshops foram especialmente aprofundados dois temas: a relação comunicação/educação e o conceito de gestão da comunicação nos espaços educativos. Finalmente, os seminários e congressos serviram como testes para a convivência entre as várias subáreas que hipoteticamente compõem o campo da inter-relação em estudo.

O conjunto dos dados levantados possibilitou vislumbrar não apenas um crescente interesse pelo assunto em questão, mas, sobretudo, a existência de um processo de sistematização teórica que apon-

Resumo: $\mathrm{O}$ autor sustenta sua argumentação na defesa do campo de inter-relação comunicação/educação, através de pensadores, filósofos, educadores, comunicólogos que têm produzido análises sobre a realidade contemporânea e a relação das Ciências Humanas e Sociais com a Educação e a Comunicação, tendo como ponto de partida a importância da comunicação na atualidade. Fundamentado teoricamente, o autor busca demonstrar como vai se configurando um campo de atuação para a educomunicação. Cita ainda a pesquisa sobre o perfil de profissionais e pesquisadores que atuam na área, desenvolvida pelo Núcleo de Comunicação e Educação da ECA/USP, entre 1997-1999 e constata o delineamento do campo comunicação/ educação na América-Latina.

Palavras-chave: educomunicação, interrelação, comunicação/educação, cidadania, educação para os meios

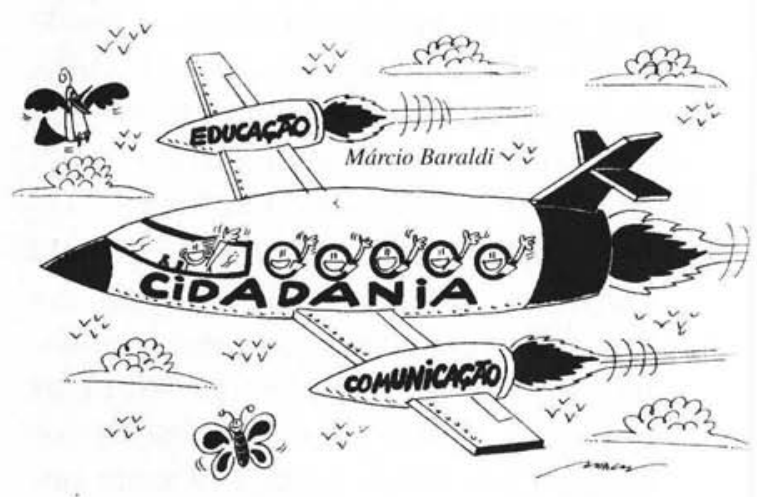

ta a interdiscursividade e a interdisciplinaridade como elementos essenciais da epistemologia do campo, evidenciados no desenho do perfil do novo profissional a ele dedicado.

Abstract. The author sustains his argumentation in the defense of a interrelationship field between communication/education, through scholars, philosophers, educators, communications students, who have produced analyses about contemporaneous reality and the relation of Human and Social Sciences with Education and Communication, having as a starting point the current importance of communications. Theoretically based, the author aims at demonstrating how the performance field for educommunication has been being set up. $\mathrm{He}$ also mentions the research that has been made on the profile of the professionals and researchers who perform in he area, developed by the ECA/USP Núcleo de Comunicação e Educação (Communication and Education Nucleus), between 1997 and 1999, and presents the lineout of the communication/education field in Latin America.

Key words: educommunication, interrelationship, communication/education, citizenship, education for the media 